\title{
Towards closing the gap between hygroscopic growth and activation for secondary organic aerosol: Part 1 - Evidence from measurements
}

\author{
H. Wex ${ }^{1}$, M. D. Petters ${ }^{2}$, C. M. Carrico ${ }^{2}$, E. Hallbauer ${ }^{1}$, A. Massling ${ }^{1, *}$, G. R. McMeeking ${ }^{2, * *}$, L. Poulain ${ }^{1}$, Z. Wu ${ }^{1}$, \\ S. M. Kreidenweis ${ }^{2}$, and F. Stratmann ${ }^{1}$ \\ ${ }^{1}$ Institute for Tropospheric Research, Leipzig, Germany \\ ${ }^{2}$ Department of Atmospheric Science, Colorado State University, Fort Collins, CO, USA \\ * now at: National Environmental Research Institute, Aarhus University, Roskilde, Denmark \\ ** now at: Centre for Atmospheric Science, University of Manchester, Manchester, UK
}

Received: 22 September 2008 - Published in Atmos. Chem. Phys. Discuss.: 13 January 2009

Revised: 5 May 2009 - Accepted: 10 June 2009 - Published: 18 June 2009

\begin{abstract}
Secondary Organic Aerosols (SOA) studied in previous laboratory experiments generally showed only slight hygroscopic growth, but a much better activity as a CCN (Cloud Condensation Nucleus) than indicated by the hygroscopic growth. This discrepancy was examined at LACIS (Leipzig Aerosol Cloud Interaction Simulator), using a portable generator that produced SOA particles from the ozonolysis of $\alpha$-pinene, and adding butanol or butanol and water vapor during some of the experiments. The light scattering signal of dry SOA-particles was measured by the LACIS optical particle spectrometer and was used to derive a refractive index for SOA of 1.45. LACIS also measured the hygroscopic growth of SOA particles up to $99.6 \%$ relative humidity (RH), and a CCN counter was used to measure the particle activation. SOA-particles were $\mathrm{CCN}$ active with critical diameters of e.g. $100 \mathrm{~nm}$ and $55 \mathrm{~nm}$ at super-saturations of $0.4 \%$ and $1.1 \%$, respectively. But only slight hygroscopic growth with hygroscopic growth factors $\leq 1.05$ was observed at $\mathrm{RH}<98 \% \mathrm{RH}$. At $\mathrm{RH}>98 \%$, the hygroscopic growth increased stronger than would be expected if a constant hygroscopicity parameter for the particle/droplet solution was assumed. An increase of the hygroscopicity parameter by a factor of 4-6 was observed in the RH-range from below $90 \%$ to $99.6 \%$, and this increase continued for increasingly diluted particle solutions for activating particles. This explains an observation already made in the past: that the relation between critical super-saturation and dry diameter for activa-
\end{abstract}

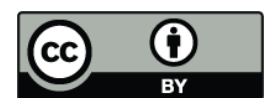

Correspondence to: $\mathrm{H}$. Wex (wex@ tropos.de) tion is steeper than what would be expected for a constant value of the hygroscopicity. Combining measurements of hygroscopic growth and activation, it was found that the surface tension that has to be assumed to interpret the measurements consistently is greater than $55 \mathrm{mN} / \mathrm{m}$, possibly close to that of pure water, depending on the different SOA-types produced, and therefore only in part accounts for the discrepancy between hygroscopic growth and CCN activity observed for SOA particles in the past.

\section{Introduction}

The atmospheric aerosol affects the Earth's climate by influencing the radiation budget directly by scattering and absorbing incoming solar radiation (direct aerosol effect) (Pilinis et al., 1995) and indirectly by affecting cloud microphysical properties (Twomey, 1977), cloud formation (Petters et al., 2006), and cloud lifetime (Albrecht, 1989) (indirect aerosol effects). Atmospheric aerosol particles consist of inorganic and organic substances, with inorganic components that are mostly water soluble at relative humidities $(\mathrm{RH})$ greater $\sim 70 \%$, and with organic components that differ widely in their solubility in water. The substances included in an atmospheric aerosol particle and their respective mass fractions depend on the formation process of the particle and on its history, as it undergoes processes such as coagulation, condensation and evaporation and cloud processing in general. One way to form particulate matter is by the oxidation of volatile organic compounds (VOCs), forming products of low and intermediate volatility that partition between

Published by Copernicus Publications on behalf of the European Geosciences Union. 
the gas and condensed aerosol phase. The particle products of these reactions are called secondary organic aerosols, or SOA. Different precursor gases lead to different SOA compounds. Oxidation of anthropogenic VOCs is thought to produce mainly short chain compounds, e.g. dicarboxylic acids with 3-6C atoms, while biogenic VOCs are believed to be precursors for longer chain compounds (Nepotchatykh and Ariya, 2002; Baltensperger et al., 2005). Among biogenic VOCs, monoterpenes such as $\alpha$-pinene are believed to be the major precursors of biogenic SOA (Sun and Ariya, 2006), and thus many studies have examined SOA generated by the oxidation of $\alpha$-pinene, either via photooxidation or ozonolysis (Virkkula et al., 1999; Saathoff et al., 2003; Baltensperger et al., 2005; Huff Hartz et al., 2005; VanReken et al. 2005; Iinuma et al., 2005; Varutbangkul et al. 2006; King et al., 2007; Prenni et al., 2007; Duplissy et al. 2008; Engelhart et al., 2008). Although SOA is comprised of many different compounds, with the exact composition depending on the precursor and oxidant, measured hygroscopic growth factors are surprisingly similar for different systems (Virkkula et al., 1999; Saathoff et al., 2003; Baltensperger et al., 2005; VanReken et al., 2005; Varutbangkul et al., 2006; Prenni et al., 2007; Engelhart et al., 2008). Typical SOA diameter growth factors are $1.1(+/-0.05)$ at RHs $\sim 90 \%$. This contrasts with measurements of the ability of SOA particles to serve as cloud condensation nuclei (CCN) (Huff Hartz et al., 2005; VanReken et al., 2005; King et al., 2007; Prenni et al., 2007; Duplissy et al., 2008; Engelhart et al., 2008), which is far greater than their hygroscopic growth factors would suggest from CCN modeling (Prenni et al., 2007). The apparent discrepancy between the observed hygroscopic growth and CCN activity could be explained, if SOA particles had surface tensions $(\sigma)$ of $\sim 30 \mathrm{mN} / \mathrm{m}$ (Huff Hartz et al., 2006; Prenni et al., 2007). This value, however, is not supported by measured surface tensions of typical SOA products, e.g. pinic acid, pinonic acid, or pinonaldehyde, which generally have values $>50 \mathrm{mN} / \mathrm{m}$ (Huff Hartz et al., 2006; Tuckermann and Cammenga, 2004). It also disagrees with surface tensions that have been reported for atmospheric samples that also were found to be larger $(>40-50 \mathrm{mN} / \mathrm{m})$ (Facchini et al., 2000; Kiss et al., 2005; Salma et al., 2006). Prenni et al. (2007) also suggested gradual dissolution of sparingly soluble compounds or highly non-ideal solution behavior due to the presence of high molecular weight compounds could explain their observations. But previous studies were limited to hygroscopic growth measurements at $\mathrm{RH}<90 \%$, so it was not possible to elucidate the origin of this discrepancy.

Here we report measurements of hygroscopic growth factors for SOA generated from the dark ozonolysis of $\alpha$-pinene conducted at the ACCENT (Aerosol Composition Change - the European Network of Excellence) infrastructure site LACIS (Leipzig Aerosol Cloud Interaction Simulator, (Stratmann et al., 2004), which allows measurements of hygroscopic growth up to RHs above 99\% (Wex et al., 2005). In addition, $\mathrm{CCN}$ activity was measured using a $\mathrm{CCN}$ counter

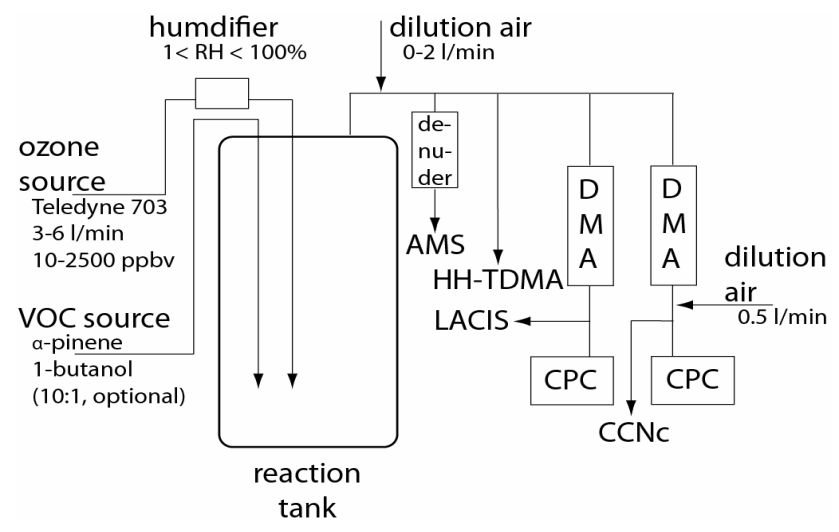

Fig. 1. Schematic of the experimental setup for the measurements.

(CCNc, Droplet Measurement Technologies, Roberts and Nenes, 2005). Using these data, we discuss the role of surface tension and hygroscopicity in cloud droplet activation using a single parameter framework (Wex et al., 2007; Petters and Kreidenweis, 2007a). Our data suggest that surface tension can only in part account for the discrepancy between hygroscopic growth and $\mathrm{CCN}$ activity. In a companion paper (Petters et al., 2009) we discuss physically plausible explanations that may explain the change of hygroscopicity between the sub- and super-saturated regimes.

\section{Measurements}

\subsection{SOA generation}

Figure 1 shows a schematic of the experimental setup for the particle generation and the measurements. Particles were generated inside a continuous flow reactor consisting of a stainless steel chamber (inner volume $\sim 12 \mathrm{~L}$ ). At a total flow of $6 \mathrm{~L} \mathrm{~min}^{-1}$ through the chamber the average residence time in the chamber was $2 \mathrm{~min}$. The reaction was steered by using two separately controlled flows, i.e. the flow rate of synthetic air containing ozone and the flow rate of synthetic air containing the organic precursor vapor, with $\alpha$-pinene as the organic precursor for the experiments described here.

The flow of synthetic air containing ozone was generated at 3-6 $\mathrm{L} \mathrm{min}^{-1}$ with a dynamic dilution calibrator (Teledyne Instruments, Model 703) where ozone concentrations could be adjusted from 10-2500 ppbv. Water vapor could be added to the chamber. If this was done, the flow of synthetic air carrying the ozone was saturated with water vapor over a water bath in a thermostated glass container. The dew point temperature $\left(T_{d}\right)$ in the reaction chamber could be influenced through adjusting the temperature of the glass container, and it was measured with a dew point mirror (Edge Tech, Model "Dew Prime I") at the chamber outlet.

The $\alpha$-pinene vapor was generated by injecting a liquid flow of $\alpha$-pinene, controlled by a microliter peristaltic pump, 
Table 1. Concentrations of the different components that were used to generate SOA during the different experiments. Different experiment numbers indicate the different days during the course of the campaign on which the experiments were done.

\begin{tabular}{lcccc}
\hline & $\begin{array}{c}\alpha \text {-pinene (and butanol, } \\
\text { if present) }\left[\mathrm{L} \mathrm{min}^{-1}\right]\end{array}$ & $\begin{array}{c}\text { ozone } \\
{\left[\mathrm{L} \mathrm{min}^{-1}\right]}\end{array}$ & $\begin{array}{c}\mathrm{H}_{2} \mathrm{O} \text { vapor } \\
{[\% \mathrm{RH}]}\end{array}$ & $\begin{array}{c}\text { dilution behind tank } \\
{\left[\mathrm{L} \mathrm{min}^{-1}\right]}\end{array}$ \\
\hline $\begin{array}{l}\text { SOA-type-1 } \\
\text { experiment } 4\end{array}$ & 0.3 & 3 & & \\
experiment 7 & 0.3 & 5 & & \\
$\begin{array}{l}\text { SOA-type-2 } \\
\text { experiment 1 }\end{array}$ & 0.2 & 2 & & \\
experiment 2 & 0.3 & 2 & & 2 \\
$\begin{array}{l}\text { SOA-type-3 } \\
\text { experiment } 8\end{array}$ & 0.3 & 5 & $69 \pm 4$ & \\
\hline
\end{tabular}

$\left(2-10 \mu \mathrm{L} \mathrm{min}^{-1}\right)$ into a stainless Swagelok tube fitting reducer (SS-200-R-2) where it evaporated into $5-10 \mathrm{~L} \mathrm{~min}^{-1}$ of dry $\left(T_{d} \sim-40^{\circ} \mathrm{C}\right.$, where $T_{d}$ denotes the dew point temperature) hydrocarbon free synthetic air (ZERO, Air Products $\mathrm{GmbH})$. A second line was added to simultaneously inject butanol into the gas stream in some experiments. Butanol reacts rapidly with any $\mathrm{OH}$ formed during the reaction of $\alpha$-pinene with $\mathrm{O}_{3}$ and thereby allows the suppression of the amount of $\mathrm{OH}$ available for the reaction with the precursor (Iinuma et al., 2005). The butanol-to- $\alpha$-pinene ratio could be adjusted by selecting the appropriate tube diameter inside the peristaltic pump. When butanol was added, the ratio of butanol-to- $\alpha$-pinene was 10:1. A small flow $\left(0.3 \mathrm{~L} \mathrm{~min}^{-1}\right)$ of the air containing $\alpha$-pinene- (and butanol-) vapor was forced into the stainless steel chamber through an orifice. In the absence of chemical reactions, $\alpha$-pinene concentrations were in excess of that of $\mathrm{O}_{3}$, i.e. $>1 \mathrm{ppmv}$, so the amount of $\mathrm{VOC}$ that reacted was controlled by the $\mathrm{O}_{3}$ concentration. The precursor gas reacted with the ozone and particles formed via homogeneous nucleation from the oxidation products. After $30 \mathrm{~min}$, a steady state particle number size distribution was observed at the reactor outlet. The setup allowed the generation of SOA mass concentrations of $3-1000 \mu \mathrm{g} \mathrm{m}^{-3}$. Variable amounts of sample flow were extracted from a port at the top of the reactor. The excess was vented, thereby maintaining the reactor close to ambient pressure.

During the experiments described here, $\alpha$-pinene (Aldrich, $98 \%$ ) was used as organic precursor. The generated SOA particles were conducted to the different instruments (described later) that characterized their properties simultaneously.

We generated SOA under three sets of reaction conditions which are summarized in Table 1:

1) reaction of $\alpha$-pinene and butanol with ozone (SOAtype-1),

2) reaction of $\alpha$-pinene with ozone (SOA-type-2), and

3 ) reaction of $\alpha$-pinene and butanol with ozone and water vapor (SOA-type-3).
The flows and concentrations of the different precursor gases are given in Table 1.

\subsection{LACIS}

LACIS consists of a laminar flow tube and an white-light optical particle spectrometer (OPS, Kiselev et al., 2005) that measures the size of particles after the passage through the tube. For this study, a flow tube length of $1 \mathrm{~m}$ was used for LACIS. Aerosol and sheath air were humidified (aerosol: MH-110-12S-4, sheath air: PH-30T-24KS, Perma Pure) to well defined dew point temperatures (reproducibility $\sim 0.01 \mathrm{~K}$ ) before entering the flow tube. The residence time of the particles in the flow tube was two seconds. The dew point temperatures and the LACIS wall temperature determine the water vapor saturation in the flow tube. LACIS was operated in its sub-saturated mode of operation (Wex et al., 2005). In this mode the wall temperature $\left(20^{\circ} \mathrm{C}\right)$ was above the dew point temperature (between $16.52^{\circ} \mathrm{C}$ and $19.99^{\circ} \mathrm{C}$ ) of the aerosol and the sheath air. Resulting RHs ranged from 80.0-99.6\%. Calibration of the RH in LACIS was performed with $\left(\mathrm{NH}_{4}\right)_{2} \mathrm{SO}_{4}$ particles with dry mobility diameters of 150 and $300 \mathrm{~nm}$. Figure 2 shows wet diameter as a function of saturation for the $150 \mathrm{~nm}$ calibration particles prior to, during, and after the campaign. The theoretical calibration curve shown in Fig. 2 is based on Köhler theory, using equations similar to those in (Wex et al., 2007), assuming non-ideal behavior of the ammonium sulfate (Pruppacher and Klett, 1997).

At the LACIS outlet, the OPS measured the size of the grown particles (Kiselev et al., 2005). The spectrometer was calibrated before and after the campaign using PSL particles of eight different sizes between $240 \mathrm{~nm}$ and $799 \mathrm{~nm}$ (Duke Scientific). To convert the OPS signal to particle diameters, the refractive index of the hydrated SOA particles must be known. Determination of the refractive index of dry SOA is described in detail in Sect. 2.4. When determining the sizes of hydrated SOA particles, we calculated the change 


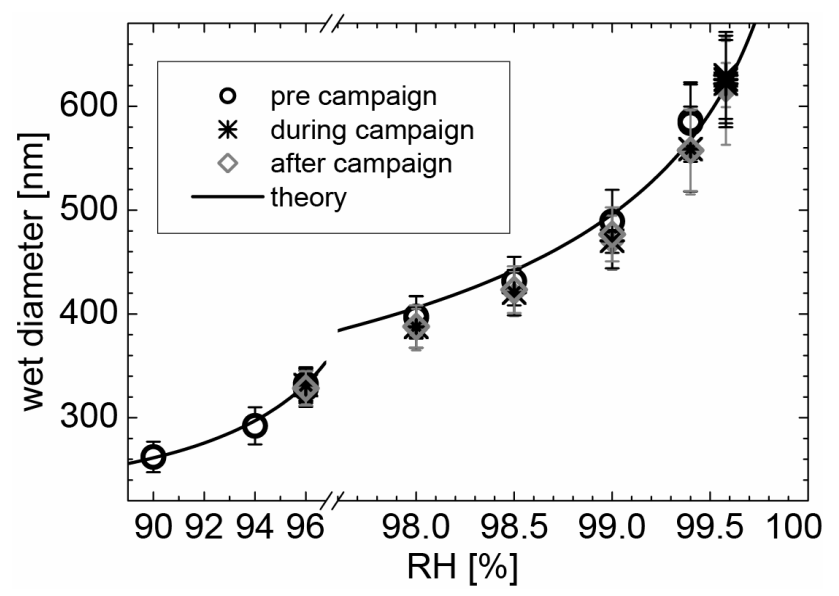

Fig. 2. Calibration of LACIS with $\left(\mathrm{NH}_{4}\right)_{2} \mathrm{SO}_{4}$ particles with a dry size of $150 \mathrm{~nm}$.

in refractive index with increasing water content using the volume mixing rule, as described in Kiselev et al. (2005).

\subsection{CCN counter}

Droplet activation is measured as a function of controlled super-saturation $(s)$ and particle dry diameter $D_{d}$ with a CCNc (Droplet Measurement Technologies, Roberts and Nenes, 2005). The generated particles are charge equilibrated and a quasi-monodisperse stream is extracted from this sample using a Vienna-type differential mobility analyzer (DMA, aerosol flow $1 \mathrm{~L} \mathrm{~min}^{-1}$, sheath air flow $10 \mathrm{~L} \mathrm{~min}^{-1}$ ). The flow containing the quasi-monodisperse particle distribution is split, with equal concentrations being sent to the CCNc sampling at fixed super-saturation and to a Condensation Particle Counter (CPC, TSI 3010) to measure total number concentration $(\mathrm{CN})$. For each mobility-selected size, the ratio of $\mathrm{CCN}$ to $\mathrm{CN}$ concentration defines the socalled CCN activated fraction. An inversion model that describes the transfer of polydisperse charge-equilibrated particles through an ideal differential mobility analyzer followed by transit through an ideal $\mathrm{CCNc}$ is used to find the activation diameter at the specified super-saturation (Petters et al., 2007b). Figure 3 shows example activation curves for a set of measurements on SOA-type-3 (Table 1) for four selected temperature gradients in the $\mathrm{CCNc}$. Each temperature gradient is related to a defined chamber super-saturation via calibrations with ammonium sulfate. The calibrations assume that the relationship between critical super-saturation and dry diameter for ammonium sulfate is described by $\kappa=0.6$ (Petters and Kreidenweis, 2007a), based on water activity versus composition relationship in the aerosol inorganic model (Clegg et al., 1998). Figure 4 shows the results from the different calibrations, i.e. indicates the good reproducibility of the selected CCNc super-saturation.

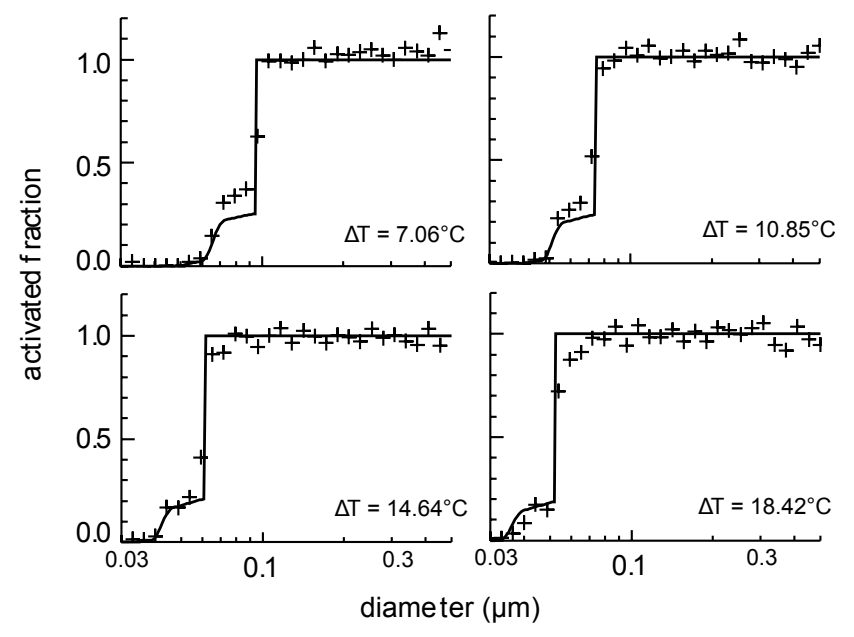

Fig. 3. Measured CCNc response curves for four temperature gradients (exemplarily shown for measurements on SOA-type-3), represented as symbols. Also shown are the modeled $\mathrm{CCNc}$ response curves based on the transfer of polydisperse charge-equilibrated particles through an ideal differential mobility analyzer followed by transit through an ideal CCN instrument (Petters et al., 2007b).

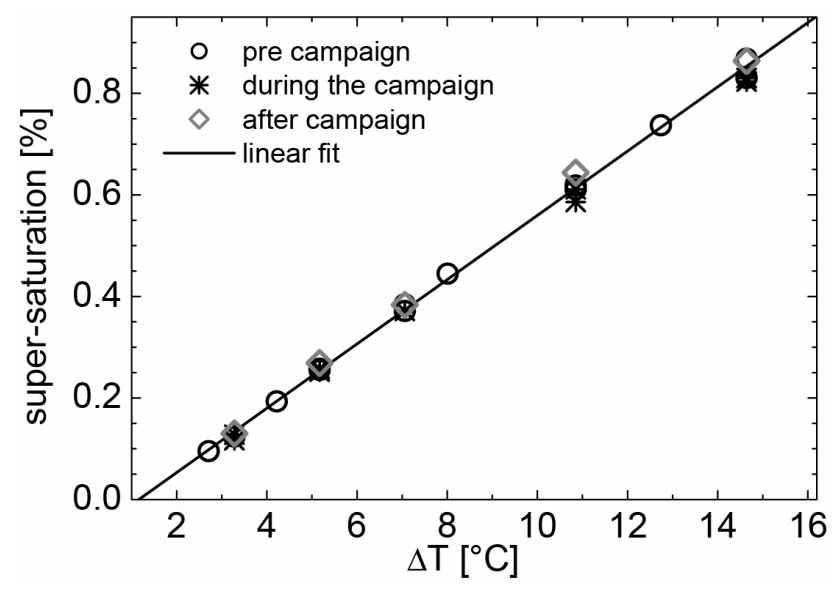

Fig. 4. Calibration of the $\mathrm{CCNc}$ with $\left(\mathrm{NH}_{4}\right)_{2} \mathrm{SO}_{4}$ particles. During the calibration, the dry particle diameter was varied at different adjusted values of $\Delta \mathrm{T}$ in the instrument.

\subsection{Determining the refractive index}

For the determination of the refractive index of SOA, measurements with the LACIS OPS were done for dry particles of different sizes, selected with a DMA. The SOA particles used in this context were of the SOA-type-2, generated with the above described setup. In addition to SOA particles, we also sampled dry particles with known real refractive index $(n)$, consisting of either PSL $(n=1.59)$, ammonium sulfate $(n=1.53)$, or succinic acid $(n=1.41)$. These particles were generated with an atomizer and subsequently dried in a diffusion drier prior to size selection in the DMA. LACIS was 


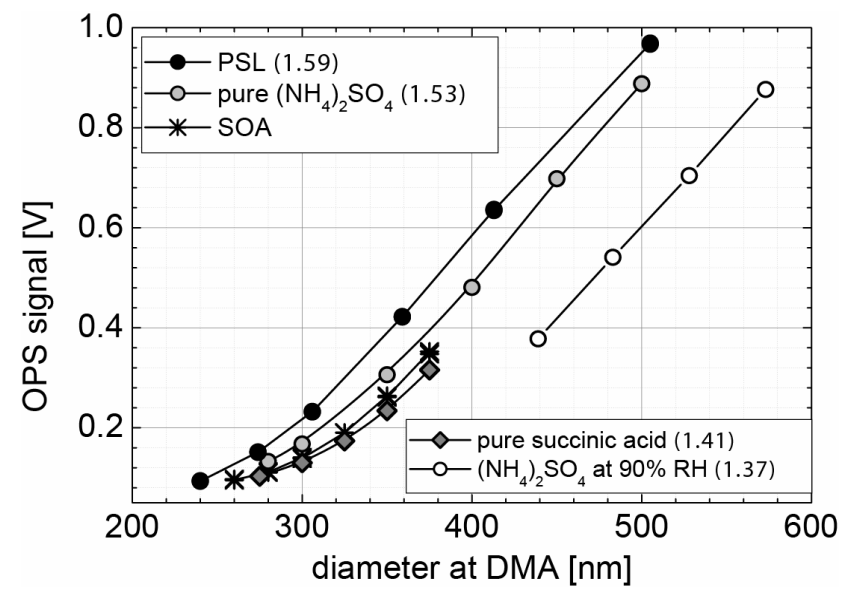

Fig. 5. Measured OPS signals in dependence on the mobility diameter selected with a DMA for different substances.

operated without humidifying the aerosol or sheath air flows. Figure 5 shows measured signals for the different dry particle types and sizes, as a function of the mobility diameter as selected with the DMA. Values for aqueous ammonium sulfate particles with different dry diameters, humidified to $90 \% \mathrm{RH}$ in LACIS $(n=1.37)$, are also shown. The amount of scattered light measured by the OPS depends on particle diameter and refractive index. Figure 5 shows, that PSL and ammonium sulfate particles have stronger scattering signals than SOA at the same mobility diameter, while succinic acid and hydrated ammonium sulfate particles have weaker scattering signals than SOA at the same mobility diameter. The real component of the refractive index for dry SOA particles generated in our study should fall between 1.41 (succinic acid) and 1.53 (ammonium sulfate). We calculated OPS response curves for different refractive indices $(1.55,1.5$. and 1.45). Figure 6 shows the diameters that were derived when using the different response curves, in comparison to the corresponding mobility diameters. Using a refractive index of 1.45 for the dry SOA particles yielded the best agreement between the mobility diameters and the optically derived diameters. This is consistent with the results presented in Fig. 5 and therefore a value of 1.45 was used for the evaluation of the LACIS data in our analysis. This value is also comparable to values given in literature, where a value of $n=1.44$ was given in Schnaiter et al. (2003) as being applicable for SOA generated by ozonolysis of $\alpha$-pinene. A value of $n=1.42$ has been found for background aerosol in the Amazon, for which more than $50 \%$ of the mass were organic matter (Guyon et al., 2003).

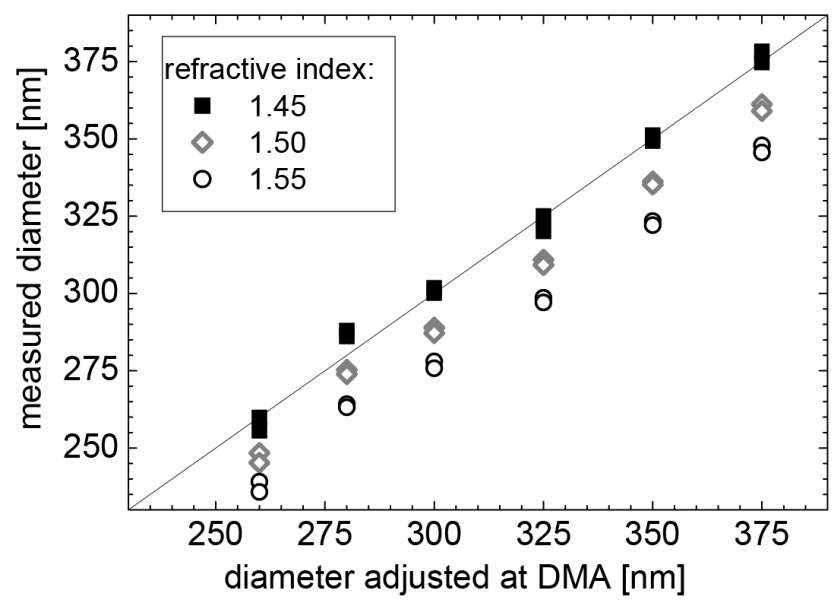

Fig. 6. Measurements with the LACIS OPS of SOA particles of different dry sizes, adjusted at a DMA. Data evaluation was done for OPS transfer functions calculated for different refractive indices.

\section{Data analysis}

The Köhler equation relates the saturation ratio, $S=\mathrm{RH} / 100$, to water activity and the Kelvin term

$S=a_{w} \exp \left(\frac{4 \sigma_{s / a} M_{w}}{R T \rho_{w} D}\right)$

where $a_{w}$ is the activity of water in solution, $\rho_{w}$ is the density of water, $M_{w}$ is the molecular weight of water, $\sigma_{s / a}$ is the surface tension of the solution/air interface, $R$ is the universal gas constant, $T$ is temperature, and $D$ is the diameter of the droplet. Here we use the single parameter framework to analyze our data. Several essentially equivalent expressions have been suggested in the literature (Rissler et al., 2006; Wex et al., 2007; Petters and Kreidenweis, 2007a) and could be used in this context. Here we use both, $\rho_{\text {ion }}$ (Wex et al., 2007) and $\kappa$ (Petters and Kreidenweis, 2007a) to parameterize the water activity in dependence on the dry and wet particle diameter:

$a_{w}=\exp \left(-\rho_{\text {ion }} \frac{M_{w}}{\rho_{w}} \times \frac{D_{d}^{3}}{D^{3}-D_{d}^{3}}\right)$

$a_{w}=\frac{D^{3}-D_{d}^{3}}{D^{3}-D_{d}^{3}(1-\kappa)}$

where $\rho_{\text {ion }}=\phi v \rho_{s} / M_{s}$ (Wex et al., 2007), with the osmotic coefficient $\phi$ (accounting for non-ideality of the solution), the number of ions per solute molecule $v$, and with the density and the molecular weight of the solute, $\rho_{s}$ and $M_{s}$, respectively.

The parameters $\rho_{\text {ion }}$ and $\kappa$ are tied to the equation that defines them and thus the two approaches are not identical. However, for $a_{w}>0.95: \rho_{\mathrm{ion}} M_{w} / \rho_{w} \approx \kappa$ (i.e. the relative difference between the two formulations is less than $3 \%$ if 


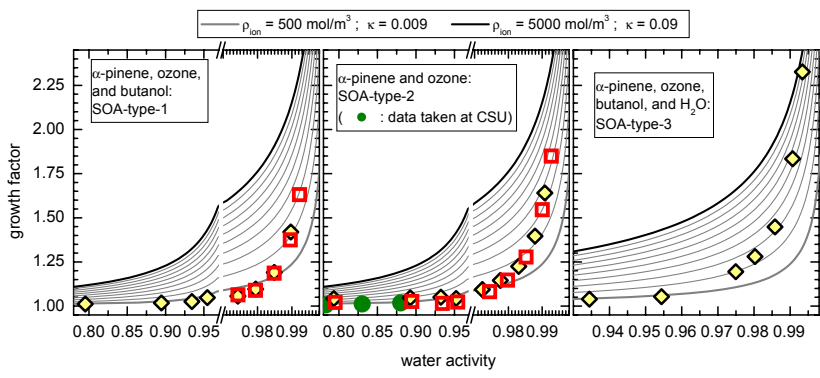

Fig. 7. Hygroscopic growth factors, depicted as a function of the water activity, measured with LACIS and with the CSU HTDMA, for three different types of SOA particles. Different symbols result from measurements that were done on different days for similar experimental conditions. Grey lines are contour lines indicating the relation between water activity and the particle growth factor for constant hygroscopicity.

$\rho_{\text {ion }} M_{w} / \rho_{w}=\kappa$ is assumed). Either Eq. (2) or (3) can be inserted into Eq. (1) to compute the Köhler curve. By solving Eq. (1) for $\rho_{\text {ion }}$ or $\kappa$, the hygroscopicity is obtained from the measured hygroscopic growth data $\left(D / D_{d}\right.$ versus $\left.\mathrm{RH}\right)$ or from the measured particle activation $\left(s_{c}\right.$, where $s_{c}=S_{c}-1$ (usually expressed as a percentage) versus selected dry diameter). The diameter of the droplet at activation is computed from the maximum of the Köhler curve. Hygroscopicity is obtained for each pair of measured data. In the remainder of this work we will refer to $\rho_{\text {ion }}$ or $\kappa$ as hygroscopicity and give numerical values for both approaches.

In this work we derive hygroscopicity for the assumption of different values of $\sigma_{s / a}$. These pairs of $\sigma_{s / a}$ and hygroscopicity then are examined further, to gain insights into the assumptions required for use of constant values for these parameters and towards the magnitude of the values that should be assigned to them.

\section{Results}

\subsection{Connecting hygroscopic growth at $<98 \%$ RH with activation}

Figure 7 shows the measured hygroscopic growth factors for the three different SOA types. The data are shown as a function of water activity to allow for comparison, because the dry particle size for experiment 1 was $250 \mathrm{~nm}$, while it was $350 \mathrm{~nm}$ for all other experiments. Water activity was calculated using Eq. (1) from the wet diameter assuming the surface tension of pure water. In the middle panel of Fig. 7, three data points were added that were obtained with a humidified tandem differential mobility analyzer (HTDMA) for SOAtype-2 particles using the same reaction vessel and a similar generation setup in previous experiments carried out at Colorado State University (CSU). The instrument and measurement protocols were identical to those used and described in

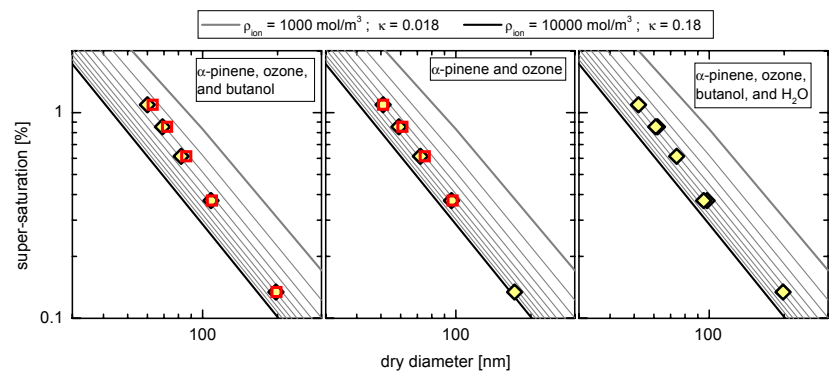

Fig. 8. Activation for three different types of SOA particles, measured with the DMT-CCNc. Different symbols result from measurements that were done on different days for similar experimental conditions. Grey lines are contour lines indicating the relation between dry particle diameter and the super-saturation needed for activation for constant hygroscopicity.

Prenni et al. (2007). The CSU HTDMA measured the hygroscopic growth in the range below $90 \% \mathrm{RH}$ and exposed particles to the set-point $\mathrm{RH}$ for a residence time of $2-3 \mathrm{~s}$. Superimposed in Fig. 7 are lines of constant hygroscopicity. The calculations were done assuming the surface tension of water to convert RH to the equivalent $a_{w}$ (Eq. 1). The growth factors cross the hygroscopicity isolines, suggesting that hygroscopicity of the particles increases systematically with increasing RH. This would also be the case had the lines been derived for a different constant surface tension. Figure 7 also shows that repetitions of experiments using the same reaction conditions produced similar growth factors. These repetitions of measurements always took place on different days, and the similarity in the measured values shows the good reproducibility of the experiments.

The hygroscopic growth of the SOA generated from the reaction of $\alpha$-pinene and butanol with ozone (SOA-type1) showed the lowest hygroscopic growth. Butanol scavenges $\mathrm{OH}$, presumably leading to less oxidation and subsequently to the production of less hygroscopic substances. On the other hand, adding water vapor to the reaction chamber (SOA-type-3) led to the production of more hygroscopic particles. The addition of water vapor has been shown to increase the hygroscopicity of unsaturated fatty acids that were oxidized with $\mathrm{O}_{3}$ in the particle phase (Vesna et al., 2007). Although the mechanism is likely different in our case, the results are similar, suggesting that relative humidity during the reaction is a potentially important variable that should be controlled in studies investigating SOA hygroscopicity. Figure 8 shows the observed critical super-saturation versus dry diameter relationships for the three different SOA types. Again, lines of constant hygroscopicity, assuming the surface tension of water, are superimposed. The decrease in critical super-saturation with increasing dry diameter is larger than expected for constant hygroscopicity, similar to that reported by VanReken et al. (2005). The ranking of CCN activation behavior of the three SOA-types is consistent with that 


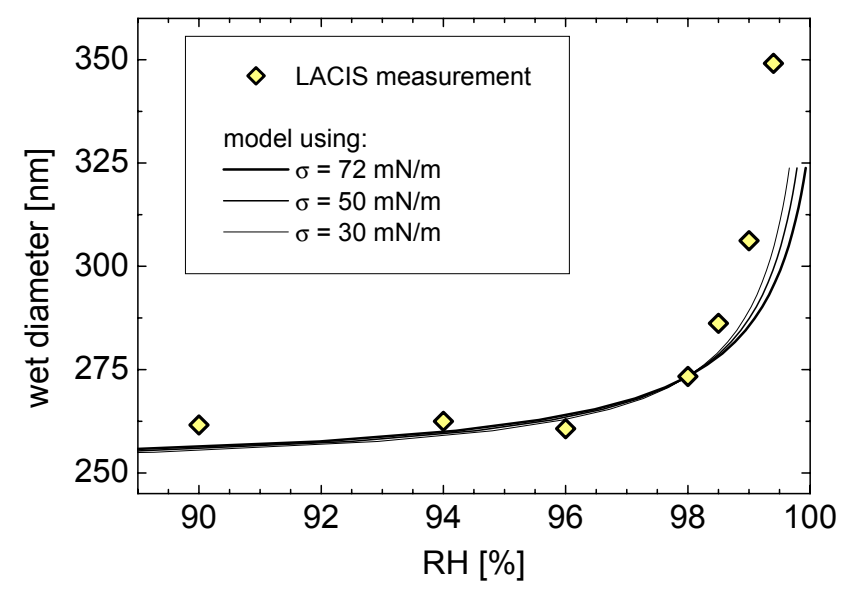

Fig. 9. Measured and modeled hygroscopic growth, with measurements from LACIS (for SOA-type-2 and a dry particle diameter of $250 \mathrm{~nm}$ ), and with the model using either the surface tension of water, $50 \mathrm{mN} / \mathrm{m}$, or $30 \mathrm{mN} / \mathrm{m}$.

observed for sub-saturated growth, that is SOA-type-2 and SOA-type-3 are more hygroscopic than SOA-type-1.

In a first step, to connect the hygroscopic growth to activation we use average values for the hygroscopicity derived from measurements in the range up to $98 \% \mathrm{RH}$, using three different values for the surface tension, 72,50 , and $30 \mathrm{mN} / \mathrm{m}$. The three resulting curves for the respective modeled hygroscopic growth and activation for experiment 1 are shown in Figs. 9 and 10, respectively, together with the measured values. For the hygroscopic growth range, the three model curves are similar up to high RHs. However, as shown in Fig. 10, the sensitivity of the activation to the surface tension is large, i.e. the three model curves differ significantly. The fact that the surface tension has a low influence on the hygroscopic growth but a large influence on the activation is inherent in the Köhler model (Wex et al., 2008). Figures 9 and 10 indicate that the discrepancy between hygroscopic growth and activation can only be explained by using a surface tension of $\sim 30 \mathrm{mN} / \mathrm{m}$, if we require the hygroscopicity parameter to be constant. This result was found for all three SOA-types examined in this study. However, the modeling presented in this section is based only on hygroscopic growth measurements at RHs below $98 \%$. We next consider the hygroscopicity of the SOA particles over the whole saturation range.

\subsection{Connecting hygroscopic growth at $>98 \%$ RH with activation}

The data in both, Figures 7 and 8 indicate an increase in hygroscopicity with increasing dilution. Figure 11 shows the hygroscopicity (i.e. $\rho_{\text {ion }}$ or $\kappa$ ) as a function of the SOAvolume-fractions (i.e. the volume of the dry SOA particle to the volume of the hydrated particle/droplet), for both

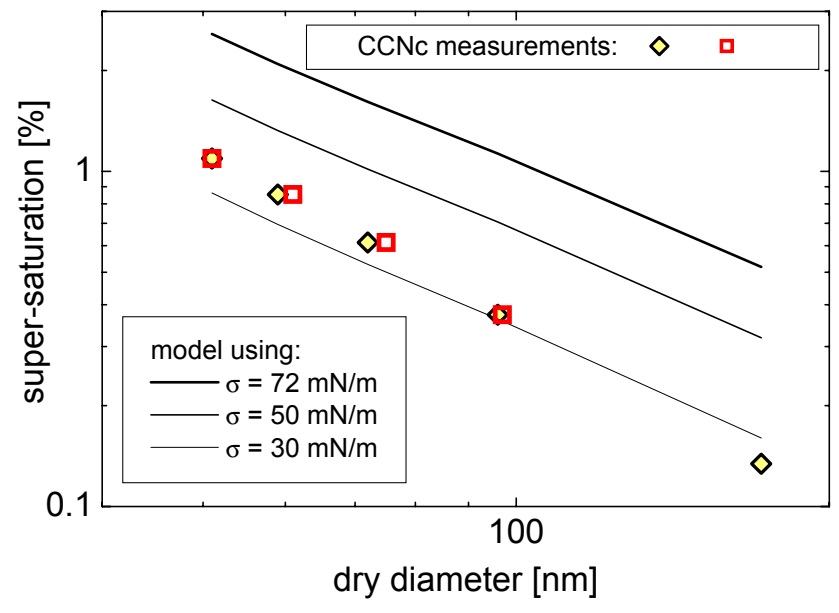

Fig. 10. Measured and modeled activation, with measurements taken from the DMT-CCNc for SOA-type-2, and with the model using either the surface tension of water, $50 \mathrm{mN} / \mathrm{m}$, or $30 \mathrm{mN} / \mathrm{m}$.

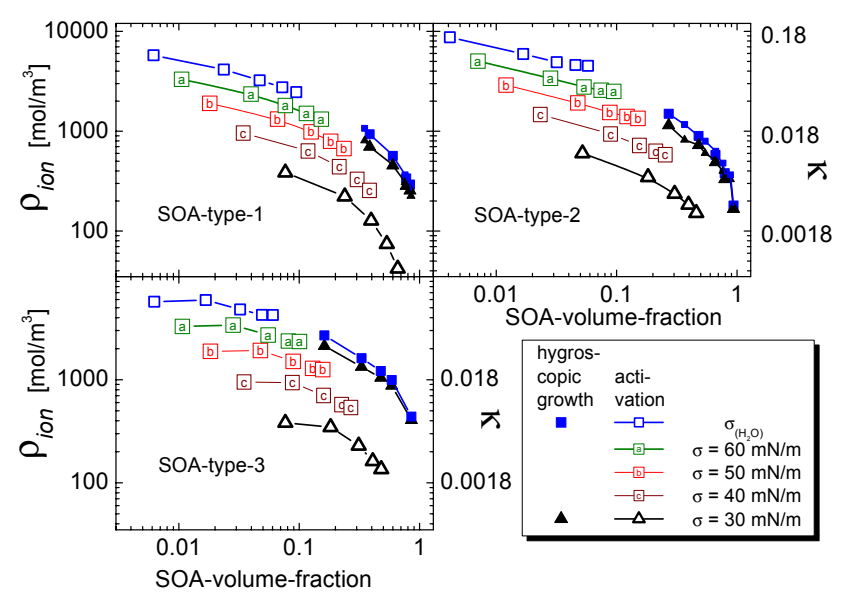

Fig. 11. Hygroscopicity for the different SOA-types, given as $\rho_{\text {ion }}$ and as $\kappa$, depicted over the SOA-volume-fraction. Values were derived from measured hygroscopic growth (filled symbols) and measured activation (open symbols) for different assumptions on $\sigma_{s / a}$ (see legend).

sub- and super-saturated measurements, for all three SOA types. Data based on measured hygroscopic growth factors are shown as filled symbols, while data based on measured activation are shown as open symbols. For the $\mathrm{CCNc}$ measurements, SOA-volume-fractions were derived from the diameters of the droplets at the point of activation calculated from the maximum of Eq. (1). Calculations were done for a range of different values of surface tension, from $30 \mathrm{mN} / \mathrm{m}$ up to the value of pure water. Since hygroscopicities derived from hygroscopic growth data only weakly depend on the assumed surface tension (Wex et al., 2008), the obtained hygroscopicity values only differ slightly for the two extreme surface tension values ( 72 and $30 \mathrm{mN} / \mathrm{m}$ ). In contrast, 


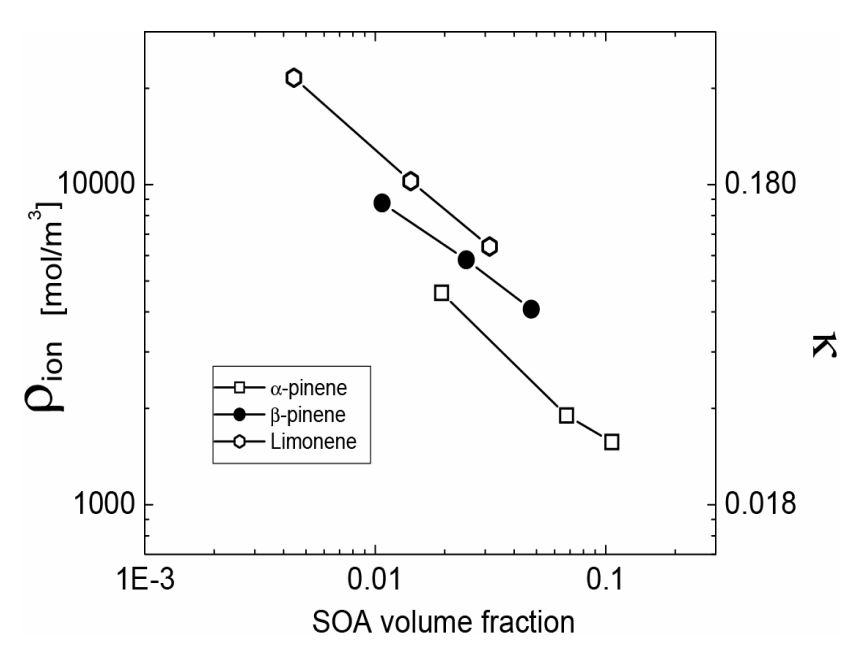

Fig. 12. Values of hygroscopicity versus the SOA-volume-fraction for SOA produced from different precursors, derived for data given in VanReken et al. (2005) and assuming $\sigma_{s / a}=72 \mathrm{mN} / \mathrm{m}$.

hygroscopicity derived from the critical super-saturation/dry diameter data pairs is sensitive to the assumed surface tension. Therefore hygroscopicity was also derived for intermediate values of surface tension (i.e. for $30,40,50,60$, and $72 \mathrm{mN} / \mathrm{m}$ ). Figure 11 shows that the best-fit hygroscopicity increases as the solutions become more diluted. Hygroscopicity derived from hygroscopic growth data below $90 \% \mathrm{RH}$ to that derived at $99.6 \%$ increases by a factor of 4-6. Including droplet activation data the increase is even greater. The increase within the activation range is comparable to what has been observed by VanReken et al. (2005) as shown in Fig. 12 where we plot their data in a manner similar to Fig. 11 . VanReken et al. (2005) noted that: "the activation properties of the SOA generated in this study are extremely sensitive to particle size; the same change in the diameter produces a much greater change in the SOA than for the singlecomponent aerosols". This strong sensitivity to dry diameter, i.e. the steeper relation between critical super-saturation and dry diameter (compared to that expected for constant hygroscopicity, see Fig. 8), is a manifestation of the underlying change of the particle hygroscopicity for these solutions. Our analyses have assumed a constant surface tension with composition. Although a concentration dependent surface tension cannot be ruled out, it would not balance the observed changes in hygroscopicity. Had we instead assumed a constant hygroscopicity (that would be equivalent to horizontal lines in Fig. 11), decreasing values of surface tension towards more dilute solutions would be needed to explain the observations. This trend is opposite to what is typically observed for aqueous organic solutions, namely surface tension is observed to increase with dilution from lower values towards that for pure water. Therefore, the changes in surface tension needed to fit our data under the assumption of constant hygroscopicity are unlikely to occur. Although the underlying

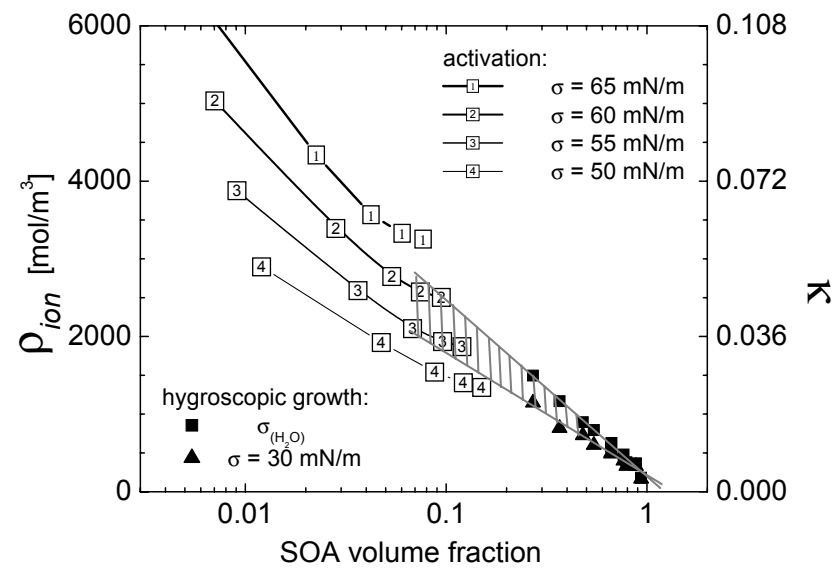

Fig. 13. Data similar to those shown in Fig. 11, with linear axis scaling, showing the derived hygroscopicity for SOA-type-2, and a linear extension of the hygroscopicity derived from measured hygroscopic growth (grey lines). The grey area envelopes the extreme values for assuming surface tension of water and $\sigma_{s / a}=30 \mathrm{mN} / \mathrm{m}$.

physical reasons for the observed increase in hygroscopicity are unknown, it seems reasonable to expect a smooth transition between hygroscopicity at different dilutions as shown in Fig. 11. Surface tension values of $30 \mathrm{mN} / \mathrm{m}$ result in discontinuities between the fitted data in the sub- and supersaturated regimes. An illustrative example for this is given in Fig. 13, which shows an enlargement of some of the data of Fig. 11 for SOA-type-2. It can be seen clearly, that values for the surface tension greater $55 \mathrm{mN} / \mathrm{m}$ should be expected. For the more hygroscopic SOA-type-3, even larger values for the surface tension are required, exceeding $65 \mathrm{mN} / \mathrm{m}$. These values do not contradict those obtained for single compounds that are expected to be present in SOA (Huff Hartz et al., 2006; Tuckermann and Cammenga, 2004).

\section{Discussion}

The apparent discrepancy between sub- and super-saturated hygroscopic growth for SOA generated in the laboratory from the ozonolysis of monoterpenes is supported by a growing body of studies on these systems. Reduced surface tensions likely do play a role in the droplet activation process but can only account for part of the dilution dependent hygroscopicity differences. Hygroscopicity, as defined by our single-parameter models, increases by at least a factor of 4-6 between RH 90\% and 99.6\%, and much more, up to 20 -fold, between RH $\sim 90 \%$ and super-saturated conditions. Changes in hygroscopicity are also observed when looking at the $\mathrm{CCN}$ activation behavior of particles of different dry diameters.

Despite this complexity, our $\mathrm{CCN}$ data are close to the range of hygroscopicity of $\kappa=0.1 \pm 0.04$ (fit by assuming the surface tension of water) that was suggested for modeling 
purposes by Prenni et al. (2007). $\kappa \sim 0.1$ appears to also well fit the CCN activation data for $\alpha$-pinene SOA in internal mixtures with inorganic substances (King et al., 2007), where 0.1 was given as the value that should be used for the SOA component when calculating particle hygroscopicity for internally mixed particles based on the volume mixing rule (Petters and Kreidenweis, 2007a). This $\kappa \sim 0.1$ corresponds to the value for surface tension to be that of water. Our analysis suggests that surface tension at the point of activation may be as low as $55 \mathrm{mN} / \mathrm{m}$, based on our assumed models of particle composition and on stipulation of a monotonic continuous relationship between solution volume fraction and hygroscopicity. It is not clear a priori what drives this relationship, and what its functional form should be; these aspects, including gradual dissolution of different components or non-ideal solution behavior of a single aqueous phase, will be discussed further in our companion manuscript (Petters et al., 2009). The inability to differentiate between alternative models using our data alone is largely caused by the inability to measure the wet critical diameter, and hence the water content, at the point of cloud droplet activation. The SOA-volume-fractions obtained from $\mathrm{CCN}$ data are uncertain since they depend on the choice of water activity model. Here we derive the volume fraction based on Eq. (1), and a suitable choice of hygroscopicity parameter in using Eq. (2) or (3), together with assuming a single aqueous phase. The so derived SOA-volume-fractions and hygroscopicities would be different if other underlying water activity models were assumed. Nevertheless, the reduced surface tensions derived here from the single parameter framework are largely consistent with those required to fit data to alternative models, as to those discussed in our companion manuscript (Petters et al., 2009).

Our data suggest that the reaction conditions affect the hygroscopicity of the aerosol, both in the sub- and supersaturated regime, indicating a decrease in hygroscopicity when butanol was used as $\mathrm{OH}$ scavenger. Experiments with and without an $\mathrm{OH}$ scavenger were also performed by Huff Hartz et al., (2006), but there were too few data points to obtain a firm conclusion on the effect on $\mathrm{CCN}$ activation. The reduced hygroscopicity is likely due to changes in composition of the formed particles. The introduction of a radical scavenger increases the rate of $\mathrm{HO}_{2}-\mathrm{RO}_{2}$ reactions at the expense of $\mathrm{RO}_{2}-\mathrm{RO}_{2}$ reactions, leading to a decrease in organic peroxides (Docherty and Ziemann, 2003; Docherty et al., 2005) and likely leading to changes in the overall extent of oxygenation. Duplissy et al. (2008) show that changes in the degree of oxidation of the organic aerosol, measured by an aerosol mass spectrometer as the ratio of $\mathrm{m} / \mathrm{z} 44$ to total organic mass, induce significant changes in aerosol hygroscopicity. Those experiments generated SOA via photooxidation of $\alpha$-pinene in the presence of $\mathrm{NO}_{\mathrm{x}}$ and the functionality of the formed aerosol depended on the precursor mass concentration. Interestingly, in the work of Duplissy et al. (2008), the sub-saturated hygroscopicity at RH 95\% measured for experiments with low $\alpha$-pinene mass concentrations (10 ppbv) was consistent with that inferred for cloud droplet activation at $\mathrm{s}=0.4 \%$, suggesting that the number of functional groups associated with the carbon chain in the SOA mixture is related to the presence of the hygroscopicity gap. This will be explored further in our companion manuscript. However, organic aerosol mass concentrations in different experiments we conducted varied from 3 to $1000 \mu \mathrm{g} / \mathrm{m}^{3}$, but we did not observe significant changes in LACIS- or CCNc-derived hygroscopicities. This is consistent with the observation of King et al. (2009), who examined $\alpha$-pinene $/ \mathrm{O}_{3}$ (dark ozonolysis) particles that were internally mixed with ammonium sulfate, and who only observed an effect on hygroscopicity at mass concentrations that were lower than those achieved in our study.

The extend to which different compounds (differing in their functional groups) were present in SOA in our experiment, as compared to SOA examined in Duplissy et al. (2008) or present in the atmosphere, can depend on the actual precursors and on the conditions under which SOA formation and subsequent aging takes place. Nevertheless, our work clarified the origin of the previously often reported gap between low hygroscopic growth and good CCN activity of laboratory produced SOA particles. It raises a note of caution for future atmospheric studies by pointing out that assuming a constant hygroscopicity over the whole range from water sub- to super-saturation might be erroneous.

\section{Conclusion}

SOA particles generated by the dark ozonolysis of $\alpha$-pinene were examined. Three reaction conditions were used to generate the SOA: 1) presence of an $\mathrm{OH}$ scavenger, 2) absence of an $\mathrm{OH}$ scavenger, and 3) presence of additional water vapor during the reaction. The optical particle spectrometer of LACIS was used to obtain signals from dry SOAparticles, and these measurements were used to derive the real part of the refractive index for SOA of 1.45 for use in subsequent data analyses for aqueous SOA particles. LACIS was used to measure the hygroscopic growth of SOA particles in the range up to $99.6 \% \mathrm{RH}$, and a CCNc determined the particles activation behavior. Similar to previous studies, the SOA particles showed weak hygroscopic growth for $\mathrm{RH}<98 \%$. However, the hygroscopic growth depended on the reaction conditions, with the observed hygroscopicity ranked as SOA-type- $1<$ SOA-type- $2<$ SOA-type-3. SOAtype- 1 , the one produced from $\alpha$-pinene under the presence of butanol grew the least, while SOA-type-3, produced under the additional presence of water vapor, grew the most. At $\mathrm{RH}>98 \%$, the hygroscopic growth increased more than would be expected if a constant hygroscopicity in the particle/droplet solution was assumed. Consistent with previous studies, SOA-particles were more $\mathrm{CCN}$ active than suggested by their sub-saturated growth factors at $\mathrm{RH}<98 \%$. An 
increase in the best-fit hygroscopicity parameter by a factor of 4-6 was observed in the RH range from below $90 \%$ to $99.6 \%$, and the best-fit hygroscopicity parameters continued to increase with dilution for activating particles.

This increase in hygroscopicity with increasing aerosol water content explains the observation already made in previous studies, that the relation between critical super-saturation and dry diameter for activation is steeper than what would be expected for a constant value of the hygroscopicity. Assuming smooth variations in the hygroscopicity parameter with dilution, plausible values of surface tension at activation are $\geq 60 \mathrm{mN} / \mathrm{m}$ for SOA produced in the presence of butanol, $\geq 55 \mathrm{mN} / \mathrm{m}$ for SOA produced by the pure ozonolysis of $\alpha$ pinene, and $\geq 65 \mathrm{mN} / \mathrm{m}$ for SOA produced in the presence of butanol and water vapor. These surface tensions are comparable to those measured for single compounds that comprise SOA. Our study indicates that a reduction of the surface tension of particles to values below $55 \mathrm{mN} / \mathrm{m}$ due to the presence of SOA is unlikely, especially for atmospheric particles that do not consist of pure SOA.

Acknowledgements. This work was funded in part by the National Science Foundation under grant ATM-0436196. GRM was supported by a US Graduate Research Environmental Fellowship (GREF) funded by the US Department of Energy's Global Change Education Program. Furthermore the project was partly supported by EUROCHAMP (Integration of European Simulation Chambers for Investigating Atmospheric Processes). Logistical support was provided from the ACCENT (Atmospheric Composition Change, the European Network of Excellence) program Access to Infrastructures.

Edited by: K. Lehtinen

\section{References}

Albrecht, B. A.: Aerosols, cloud microphysics, and fractional cloudiness, Science, 245, 1227-1230, 1989.

Baltensperger, U., Kalberer, M., Dommen, J., Paulsen, D., Alfarra, M. R., Coe, H., Fisseha, R., Gascho, A., Gysel, M., Nyeki, S., Sax, M., Steinbacher, M., Prevot, A S. H., Sjögren, S., Weingartner, E., and Zenobi, R.: Secondary organic aerosols from anthropogenic and biogenic precursors, Faraday Discuss., 130, 265-278, doi:10.1039/b417367h, 2005.

Clegg, S. L. and Brimblecombe, P.: Thermodynamic model of the system $\mathrm{H}^{+}-\mathrm{NH}_{4}^{+}-\mathrm{Na}^{+}-\mathrm{SO}_{4}^{2-}-\mathrm{NO}_{3}^{-}-\mathrm{Cl}^{-}-\mathrm{H}_{2} \mathrm{O}$ at tropospheric temperatures, J. Phys. Chem., 102(12), 2155-2171, 1998.

Docherty, K. S. and Ziemann, P. J.: Effects of stabilized Criegee intermediate and $\mathrm{OH}$ radical scavengers on aerosol formation from reactions of beta-pinene with O-3, Aerosol Sci. Technol., 37(11), 877-891, 2003.

Docherty, K. S., Wu, W., Lim, Y. B., and Ziemann, P. J.: Contributions of organic peroxides to secondary aerosol formed from reactions of monoterpenes with $\mathrm{O}_{3}$, Environ. Sci. Technol., 39(11), 4049-4059, 2005.

Duplissy, J., Gysel, M., Alfarra, M. R., Dommen, J., Metzger, A., Prevot, A. S. H., Weingartner, E., Laaksonen, A., Raatikainen,
T., Good, N., Turner, S. F., McFiggans, G., and Baltensperger, U.: Cloud forming potential of secondary organic aerosol under near atmospheric conditions, Geophys. Res. Lett., 35, L03818, doi:10.1029/2007GL031075, 2008.

Engelhart, G. J., Asa-Awuku, A., Nenes, A., and Pandis, S. N.: $\mathrm{CCN}$ activity and droplet growth kinetics of fresh and aged monoterpene secondary organic aerosol, Atmos. Chem. Phys., 8, 95-135, 2008, http://www.atmos-chem-phys.net/8/95/2008/.

Facchini, M. C., Decesari, S., Mircea, M., Fuzzi, S., and Loglio, G.: Surface tension of atmospheric wet aerosol and cloud/fog droplets in relation to their organic carbon content and chemical composition, Atmos. Environ., 34, 4853-4857, 2000.

Guyon, P., Boucher, O., Graham, B., Beck, J., Mayol-Bracero, O. L., Roberts, G. C., Maenhaut, W., Artaxo, P., and Andreae, M. O.: Refractive index of aerosol particles over the Amazon tropical forest during LBA-EUSTACH 1999, J. Aerosol Sci., 34, 883907, 2003.

Huff Hartz, K. E., Rosenorn, T., Ferchak, S. R., Raymond, T. M., Bilde, M., Donahue, N. M., and Pandis, S. N.: Cloud condensation nuclei activation of monoterpene and sesquiterpene secondary organic aerosol, J. Geophys. Res., 110, D14208, doi:10.1029/2004JD005754, 2005.

Huff Hartz, K. E., Tischuk, J. E., Chan, M. N., Chan, C. K., Donnahue, N. M., and Pandis, S. N.: Cloud condensation nuclei activation of limited solubility organic aerosol, Atmos. Environ., 40, 605-617, 2006.

Iinuma, Y., Böge, O., Miao, Y., Sierau, B., Gnauk, T., and Herrmann, H.: Laboratory studies on secondary organic aerosol formation from terpenes, Faraday Discuss., 130, 279-294, doi:210.1039/b502160j, 2005.

King, S. M., Rosenorn, T., Shilling, J. E., Chen, Q. C., and Martin, S. T.: Cloud condensation nucleus activity of secondary organic aerosol particles mixed with sulfate, Geophys. Res. Lett., 34, L24806, doi:10.1029/2007GL030390, 2007.

King, S. M., Rosenoern, T., Shilling, J. E., Chen, Q., and Martin, S. T.: Increased cloud activation potential of secondary organic aerosol for atmospheric mass loadings, Atmos. Chem. Phys., 9, 2959-2971, 2009,

http://www.atmos-chem-phys.net/9/2959/2009/.

Kiselev, A., Wex, H., Stratmann, F., Nadeev, A., and Karpushenko, D.: Whitelight optical particle spectrometer for in situ measurement of condensational growth of aerosol particles, Appl. Opt., 44(22), 4693-4701, 2005.

Kiss, G., Tombacz, E., and Hansson, H.-C.: Surface tension effects of humic-like substances in the aqueous extract of tropospheric fine aerosol, J. Atmos. Chem., 50, 279-294, doi:10.1007/s10874-005-5079-5, 2005.

Nepotchatykh, O. V. and Ariya, P. A.: Degradation of dicarboxylic acids (C2-C9) upon liquid-phase reactions with $\mathrm{O}_{3}$ and its atmospheric implications, Environ. Sci. Technol., 36(15), 3265-3269, 2002.

Petters, M. D., Snider, J. R., Stevens, B., Vali, G., Faloona, I., and Russell, L. M.: Accumulation mode aerosol, pockets of open cells, and particle nucleation in the remote subtropical $\mathrm{Pa}$ cific marine boundary layer, J. Geophys. Res., 111, D02206, doi:10.1029/2004JD005694, 2006.

Petters, M. D. and Kreidenweis, S. M.: A single parameter representation of hygroscopic growth and cloud condensation nucleus 
activity, Atmos. Chem. Phys., 7, 1961-1971, 2007a,

http://www.atmos-chem-phys.net/7/1961/2007/.

Petters, M. D., Prenni, A. J., DeMott, P. J., and Kreidenweis, S. M.: On measuring the critical diameter of cloud condensation nuclei using mobility selected aerosol, Aerosol Sci. Technol., 41(19), 907-913, 2007b.

Petters, M. D., Wex, H., Carrico, C. M., Hallbauer, E., Massling, A., McMeeking, G. R., Poulain, L., Wu, Z., Kreidenweis, S. M., and Stratmann, F.: Towards closing the gap between hygroscopic growth and activation for secondary organic aerosol - Part 2: Theoretical approaches, Atmos. Chem. Phys., 9, 3999-4009, 2009, http://www.atmos-chem-phys.net/9/3999/2009/.

Pilinis, C., Pandis, S. N., and Seinfeld, J. H.: Sensitivity of direct climate forcing by atmospheric aerosols to aerosol size and composition, J. Geophys. Res., 100, 18739-18754, 1995.

Prenni, A. J., Petters, M. D., Kreidenweis, S. M., DeMott, P., and Ziemann, P. J.: Cloud droplet activation of secondary organic aerosol, J. Geophys. Res., 112, D10223, doi:10.1029/2006JD007963, 2007.

Pruppacher, H. R. and Klett, J. D.: Microphysics of Clouds and Precipitation, Kluwer Academic Publishers, Dordrecht, The Netherlands, 109-115, 1997.

Rissler, J., Vestin, A., Swietlicki, E., Fisch, G., Zhou, J., Artaxo, P., and Andreae, M. O.: Size distribution and hygroscopic properties of aerosol particles from dry-season biomass burning in Amazonia, Atmos. Chem. Phys., 6, 471-491, 2006, http://www.atmos-chem-phys.net/6/471/2006/.

Roberts, G. and Nenes, A.: A continuous-flow streamwise thermalgradient CCN chamber for atmospheric measurements, Aerosol Sci. Tech., 39, 206-221, 2005.

Saathoff, H., Neumann, K.-H., Schnaiter, M., Schöck, W., Möhler, O., Schurath, U., Weingartner, E., Gysel, M., and Baltensperger, $\mathrm{U}$.: Coating of soot and $\left(\mathrm{NH}_{4}\right)_{2} \mathrm{SO}_{4}$ particles by ozonolysis products of $\alpha$-pinene, J. Aerosol Sci., 34, 1297-1321, 2003.

Schnaiter, M., Horvath, H., Möhler, O., Naumann, K.-H., Saathoff, H., and Schöck, O. W.: UV-VIS-NIR spectral optical properties of soot and soot-containing aerosols, J. Aerosol Sci., 34, 14211444, 2003.

Salma, I., Ocskay, R., Varga, I., and Maenhaut, W.: Surface tension of atmospheric humic-like substances in connection with relaxation, dilution, and solution ph, J. Geophys. Res., 111, D23205, doi:10.1029/2005JD007015, 2006.

Stratmann, F., Kiselev, A., Wurzler, S., Wendisch, M., Heintzenberg, J., Charlson, R. J., Diehl, K., Wex, H., and Schmidt, S.: Laboratory studies and numerical simulations of cloud droplet formation under realistic super-saturation conditions, J. Atmos. Oceanic Technol., 21, 876-887, 2004.
Sun, J., and Ariya, P. A.: Atmospheric organic and bio-aerosol as cloud condensation nuclei $(\mathrm{CCN})$ : A review, Atmos. Environ., 40, 795-820, 2006.

Tuckermann, R. and Cammenga, H. K.: The surface tension of aqueous solutions of some atmospheric water-soluble organic compounds, Atmos. Environ., 38, 6135-6138, 2004.

Twomey, S.: The influence of pollution on the shortwave albedo of clouds, J. Atmos. Sci., 34, 1149-1152, 1977.

VanReken, T. M., N. L. Ng, R. C. Flagan, and J. H. Seinfeld: Cloud condensation nucleus activation properties of biogenic secondary organic aerosol, J. Geophys. Res., 110, D07206, doi:10.1029/2004JD005 465, 2005.

Varutbangkul, V., Brechtel, F. J., Bahreini, R., Ng, N. L., Keywood, M. D., Kroll, J. H., Flagan, R. C., Seinfeld, J. H., Lee, A., and Goldstein, A. H.: Hygroscopicity of secondary organic aerosols formed by oxidation of cycloalkenes, monoterpenes, sesquiterpenes, and related compounds, Atmos. Chem. Phys., 6, 23672388, 2006, http://www.atmos-chem-phys.net/6/2367/2006/.

Vesna, O., Sjogren, S., Weingartner, E., Samburova, V., Kalberer, M., Gäggeler, H. W., and Ammann, M.: Changes of fatty acid aerosol hygroscopicity induced by ozonolysis under humid conditions, Atmos. Chem. Phys., 8, 4683-4690, 2008, http://www.atmos-chem-phys.net/8/4683/2008/.

Virkkula, A., van Dingenen, R., Raes, F., and Hjorth, J.: Hygroscopic properties of aerosol formed by oxidation of limonene, $\alpha$ pinene, and $\beta$-pinene, J. Geophys. Res., 104, 3569-3579, 1999.

Wex, H., Kiselev, A., Stratmann, F., Zoboki, J., and Brechtel, F.: Measured and modeled equilibrium sizes of $\mathrm{NaCl}$ and $\left(\mathrm{NH}_{4}\right)_{2} \mathrm{SO}_{4}$ particles at relative humidities up to $99.1 \%$, J. Geophys. Res., 110, D21212, doi:10.1029/2004JD005 507, 2005.

Wex, H., Hennig, T., Salma, I., Ocskay, R., Kiselev, A., Henning, S., Massling, A., Wiedensohler, A., and Stratmann, F.: Hygroscopic growth and measured and modeled critical super-saturations of an atmospheric HULIS sample, Geophys. Res. Lett., 34, L02818, doi:10.1029/2006GL028260, 2007.

Wex, H., Topping, D., McFiggans, G., and Stratmann, F.: The Kelvin versus the Raoult term in the Köhler equation, J. Atmos. Sci., 65, 4004-4016, doi:10.1175/2008JAS2720.1, 2008. 